05,12

\title{
Обменное смещение на границе ферро-ферримагнетик в микропроводах $\mathrm{PrDyCoFeB} / \alpha-\mathrm{Fe}$
}

\author{
(c) О.В. Коплак ${ }^{1,2}$, Е.В. Дворецкая ${ }^{1}$, Д.В. Королев ${ }^{3}$, Р.А. Валеев ${ }^{3}$, В.П. Пискорский ${ }^{3}$, \\ М.В. Гапанович ${ }^{1}$, Ю.С. Погорелец ${ }^{1}$, Р.Б. Моргунов ${ }^{1-3}$ \\ ${ }^{1}$ Институт проблем химической фризики, \\ Черноголовка, Россия \\ ${ }^{2}$ Первый московский государственный медицинский университет им. И.М. Сеченова, \\ Москва, Россия \\ ${ }^{3}$ Всероссийский институт авиационных материалов, \\ Москва, Россия \\ E-mail: o.koplak@gmail.com
}

Поступила в Редакцию 13 мая 2021 г.

В окончательной редакции 13 мая 2021 г.

Принята к публикации 13 мая 2021 г.

Обнаружено обменное смещение 50-70 Ое в двухкомпонентных микропроводах двух типов: 1) с оболочкой $\alpha$-Fe, напыленной на нанокристаллическое ядро $\mathrm{PrDyCoFeB}$ и 2) с нанокристаллической оболочкой $\operatorname{PrDyCoFeB}$ и ядром $\alpha$-Fe, самопроизвольно сформированным в процессе затвердевания расплава. При этом обменное смещение не обнаруживается в покрытых $\alpha$-Fe микрокристаллических микропроводах, преимущественно состоящих из фазы $(\mathrm{PrDy})_{2}(\mathrm{CoFe})_{14} \mathrm{~B}$. Поскольку в нанокристаллических микропроводах помимо этой фазы имеются ферримагнитные фазы $\mathrm{Dy}(\mathrm{CoFe})_{2}$ или $\mathrm{Dy}(\mathrm{CoFe})_{4} \mathrm{~B}$, возникновение обменного смещения объясняется наличием интерфейса $\alpha$-Fe с этими фазами.

Ключевые слова: ферромагнитные микропровода, магнитная анизотропия, размагничивающий фактор, намагниченность насыщения, интерфейс.

DOI: 10.21883/FTT.2021.10.51399.112

\section{1. Введение}

Многослойные ферромагнитные микропровода являются удобными объектами для создания и исследования новых магнитных состояний на границе между материалами разных типов. В частности, в двуслойных микропроводах на основе переходных металлов $\mathrm{FeSi}, \mathrm{FeCoSi}$ и др. были обнаружены эффекты переключения взаимных направлений намагниченности ядра и оболочки, а также эффекты обменного смещения [1-5]. Кроме обменного взаимодействия, действующего на интерфейсе, в двухслойных микропроводах имеет место магнитное дипольное взаимодействие между ядром и оболочкой, способное приводить к таким же феноменологическим проявлениям в полевых зависимостях намагниченности, что и при обменном взаимодействии $[6,7]$. Разделение этих эффектов представляет собой непростые экспериментальные исследования. Представляется важным проверка роли интерфейса в микропроводах на основе RE-TM-B. B [8] сообщалось о получении микропроводов $\mathrm{Ta} / \mathrm{NdFeB}$, однако отсутствие ферромагнитных или антиферромагнитных свойств у Та делает задачу получения новых функциональных свойств микропроводов безнадежной. В [9] были представлены свойства микропроводов $\mathrm{PrDyFeCoB}$, в которых при сверхбыстром охлаждении самопроизвольно образовывалась фаза $\alpha$-Fe в виде ядра, окруженного оболочкой аморфно-кристаллического сплава PrDyFeCoB. При этом в [10] сообща- лось об идентификации обменного смещения и ступенчатом переключении намагниченности, обусловленном поочередной переориентацией намагниченностей ядра и оболочки микропровода. Контакт металлов с антиферромагнитным обменом (как в $\mathrm{PrDyFeCoB}$ ) с ферромагнетиком часто приводит к появлению неколлинеарной намагниченности и обменного смещения [11], формирование которого в таких системах все еще остается не до конца объясненным. Обменное смещение петли гистерезиса в [10] может быть обусловлено неколлинеарной ориентацией спинов на интерфейсе ферромагнетика $\alpha$-Fe и ферримагнетика PrDyFeCoB. Доказательством обменного (а не магнитного дипольного) происхождения смещения петли гистерезиса в [10] послужила зависимость поля смещения петли от величины поля, в котором охлаждали образец до $2 \mathrm{~K}$. Наличие такой убывающей зависимости (поле смещения направлено против внешнего поля) и смена знака поля смещения $H_{b}$ при смене знака поля, в котором происходило охлаждение, указывают на обменное взаимодействие на интерфейсе $\alpha$-Fe/PrDyFeCoB. Вместе с тем, помимо ядра $\mathrm{Fe}$ и его интерфейса с оболочкой источниками обменного смещения могли быть интерфейсы различных фаз, формирующихся в виде включений в аморфном микропроводе. В процессе быстрого охлаждения помимо ферримагнитной фазы 2-14-1 в микропроводах формируются также фазы 1-4-1, 1-2 и др. Это делает неясным, интерфейс железа с какой из фаз приводит к появлению 
обменного смещения. Проверкой источника обменного смещения в данной работе является эксперимент, в котором сравнивается обменное смещение в микропроводе без железных включений с тем же микропроводом, на который напылен слой железа. Кроме того, при различных режимах охлаждения возникают разные фазовые составы микропровода: медленное охлаждение ведет к преимущественному появлению сравнительно крупных микрокристаллов фазы 2-14-1, а быстрое охлаждение ведет к образованию нанокристалллической и аморфной структуры с фазами 2-14-1, 1-2 и 1-4-1 [12,13]. Поэтому создание интерфейса железа с разными типами микропроводов поможет ответить на вопрос, на каком именно интерфейсе возникает обменное смещение. В настоящей работе мы предприняли попытку напыления слоя поликристаллического $\alpha$ - $\mathrm{Fe}$ на микропровода $\mathrm{PrDyFeCoB}$ c высокой и небольшой долей фазы 2-14-1.

Цель настоящей работы заключалась в установлении источника обменного смещения путем сравнительного анализа поля обменного смещения в микропроводах с разным порядком следования $\mathrm{PrDyFeCoB}$ и $\alpha$ - $\mathrm{Fe}$, а также при разном фазовом составе $\mathrm{PrDyFeCoB}$, заранее сформированном заданным режимом охлаждения сплава.

\section{2. Методика и образцы}

В опытах использовали 4 типа образцов: 1) микропровода $\mathrm{c}$ нанокристалической оболочкой $\mathrm{PrDyFeCoB}$, где включения $\alpha$-Fe возникают самопроизвольно в процессе затвердевания расплава; 2) микропровода с нанокристаллическим ядром $\mathrm{PrDyFeCoB}$ и преднамеренно напыленной оболочкой $\alpha$-Fe; 3) микропровода с микрокристаллическим ядром $\mathrm{PrDyFeCoB}$ и доминирующей фазой 2-14-1, покрытых $\alpha$ - Fe, 4) нанокристаллические микропровода $\mathrm{PrDyFeCoB}$ не содержащие оболочки или включений железа.

Методика изготовления микропроводов с аморфнонанокристаллической структурой, основана на сверхбыстром охлаждении капли расплава $\operatorname{PrDyFeCoB}$ на вращающемся холодном диске с линейной скоростью вращения $55 \mathrm{~m} / \mathrm{s}$, подробно описана в статьях [2-5], где также был проведен их структурно-химический анализ. Тем же способом были приготовлены микрокристаллические микропровода, но затем они подвергались вакуумному отжигу при $900^{\circ} \mathrm{C}$ в течение $30 \mathrm{~min}$. В аморфно-нанокристаллических микропроводах присутствовали включения фаз 2-14-1, 1-2, 1-4-1, в то время, как в микрокристаллических микропроводах доминировала фаза 2-14-1.

Микропровода диаметром $60-70 \mu \mathrm{m}$ и длиной 5-10 mm после очистки поверхности размещались в магнетронном напылителе с железной мишенью (99.99\%), где в вакууме 0.1 Ра производили напыление слоя железа толщиной 20-30 $\mu \mathrm{m}$.

Магнитные свойства микропроводов исследовали на отдельных образцах в SQUID-магнетометре MPMS XL
Quantum design при $300 \mathrm{~K}$. Магнито-оптические измерения проведены при $290 \mathrm{~K}$ с помощью микроскопа Keppa NEOARK Neomagnesia Lite BH-753 в конфигурации продольного магнито-оптического эффекта с магнитным полем до 1 кОе, направленным вдоль микропровода.

\section{3. Экспериментальные результаты}

$\mathrm{B}$ нанокристалических микропроводах $\mathrm{PrDyFeCoB}$ c ядром $\alpha-\mathrm{Fe}$, самопроизвольно сформировавшемся в процессе затвердевания расплава, с помощью микроскопа Керра иногда наблюдается магнитный гистерезис со значительным смещением при $300 \mathrm{~K}$ (рис. $1, a$ ). Однако в большинстве случаев при комнатной температуре он мал. Это связано со стохастичностью образования фазы $\alpha$-Fе при быстром охлаждении. При $2 \mathrm{~K}$ смещение петли гистерезиса надежно наблюдается с хорошей воспроизводимостью, давая возможность исследовать его в
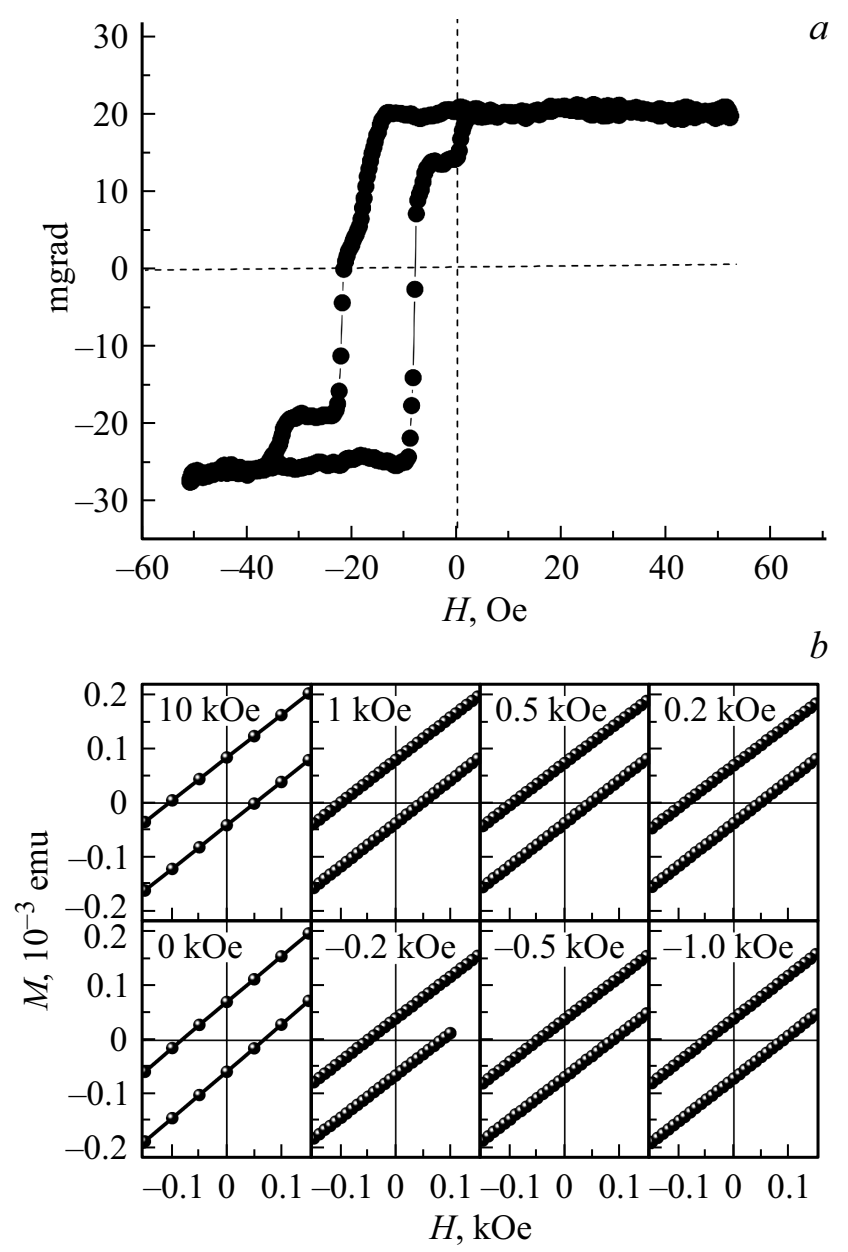

Рис. 1. $a-$ петля гистерезиса намагниченности, записанная микроскопом Керра при $300 \mathrm{~K}$ для микропровода с ядром $\alpha$-Fe и оболочкой $\mathrm{PrDyFeCoB} ; b-$ фрагменты петель гистерезиса $M(H)$, записанные при $T=2 \mathrm{~K}$ после охлаждения микропровода в различных полях от $+10 \mathrm{kOe}$ до $-10 \mathrm{kOe}$. 

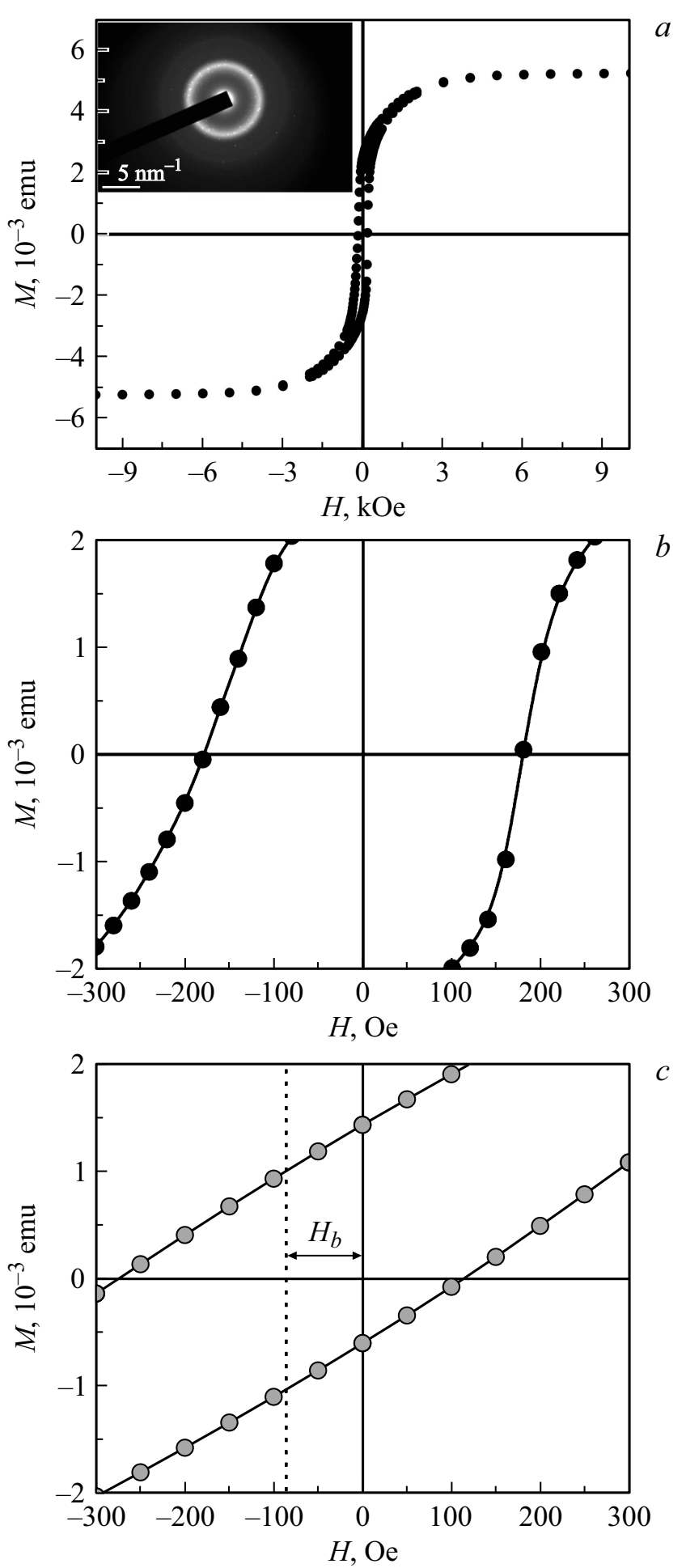

Рис. 2. $a-$ гистерезис магнитного момента $M$ аморфнонанокристаллического микропровода до напыления железа. На врезке вверху гало на электронной дифрактограмме ТЕМ; $b-$ фрагмент гистерезиса магнитного момента аморфно-нанокристаллического микропровода до напыления и $c$ - после напыления железа. Стрелкой показана величина обменного смещения. зависимости от условий экспериментов (рис. $1, b)$. При этом при $2 \mathrm{~K}$ величина смещения достигает $50 \mathrm{Oe}$, а его величина и знак зависят от величины и направления поля, при котором охлаждали микропровод. Поле обменного смещения всегда направлено против внешнего поля. Это указывает на обменный характер смещения.

Далее мы исследовали нанокристалиические микропровода, в которых ядром был многофазный сплав $\mathrm{PrDyFeCoB}$, а оболочка $\alpha$-Fe была напылена. Аморфность исходного микропровода контролировалась с помощью просвечивающего электронного микроскопа (TEM). На электронной дифрактограмме (см. врезку на рис. 2,a) видны непрерывные гало и редкие рефлексы, что свидетельствует о присутствии, как аморфной, так и нанокристалической фаз в микропроводе.

После извлечения из магнетронного напылителя, микропровода были помещены в газообразный гелий в магнетометре и измерения их магнитного момента были произведены при $2 \mathrm{~K}$ в зависимости от внешнего поля $H$. Охлаждение микропровода до $2 \mathrm{~K}$ производилось в магнитном поле 1 Ое. Полная полевая зависимость намагниченности $M$ от поля при $2 \mathrm{~K}$ приведена на рис. $2, a$. До напыления железа смещение петли гистерезиса полностью отсутствует (см. фрагмент петли гистерезиса на рис. $2, b)$, а после напыления железа возникает обменное смещение $70 \mathrm{Oe}$ (рис. 2,c). Величина обменного смещения оказывается близка к тому, которое обнаружено в предыдущей серии опытов в микропроводах с ядром $\alpha$-Fe (рис. $1, b)$.

В аморфно-нанокристаллических микропроводах до их покрытия железом перемагничивание происходит путем развития доменной структуры. На рис. 3, $a$ и $b$ приведены изображения поверхности микропроводов в поляризованном свете микроскопа Керра в различных по величине магнитных полях. При полях более $600 \mathrm{Oe}$, в которых петля гистерезиса схлопывается, домены полностью исчезают.

Отжиг аморфных микропроводов приводил к тому, что на электронной дифрактограмме вместо непрерывного гало появлялись рефлексы (врезка на рис. 4, $a$ ), которые характеризовали поликристаллическую структуру микропровода с зернами со средним размером $0.8 \mu \mathrm{m}$. При этом узкая петля гистерезиса (рис. 2, $a$ и рис. 4, кривая 1) значительно уширялась в результате отжига, так что коэрцитивная сила становилась равна 12 кОе при $300 \mathrm{~K}$ (рис. 4, кривая 2). Покрытие слоем железа такого микропровода приводило к возникновению петли гистерезиса сложной формы (рис. 4, кривая 3). Поскольку петля гистерезиса железа обладает близкой к нулю коэрцитивной силой (сходна с рис. 4, кривая 1 ), можно считать, что происходило аддитивное сложение намагниченностей железной оболочки микропровода и поликристаллического ядра. При этом не наблюдалось эффектов обменного смещения при 2 и при $300 \mathrm{~K}$, хотя небольшая ожидаемая величина которых $\sim 50-70$ Ое (см. рис. 2) вполне могла быть обнаружен при имеющейся точности измерений. 
$a$

$b$

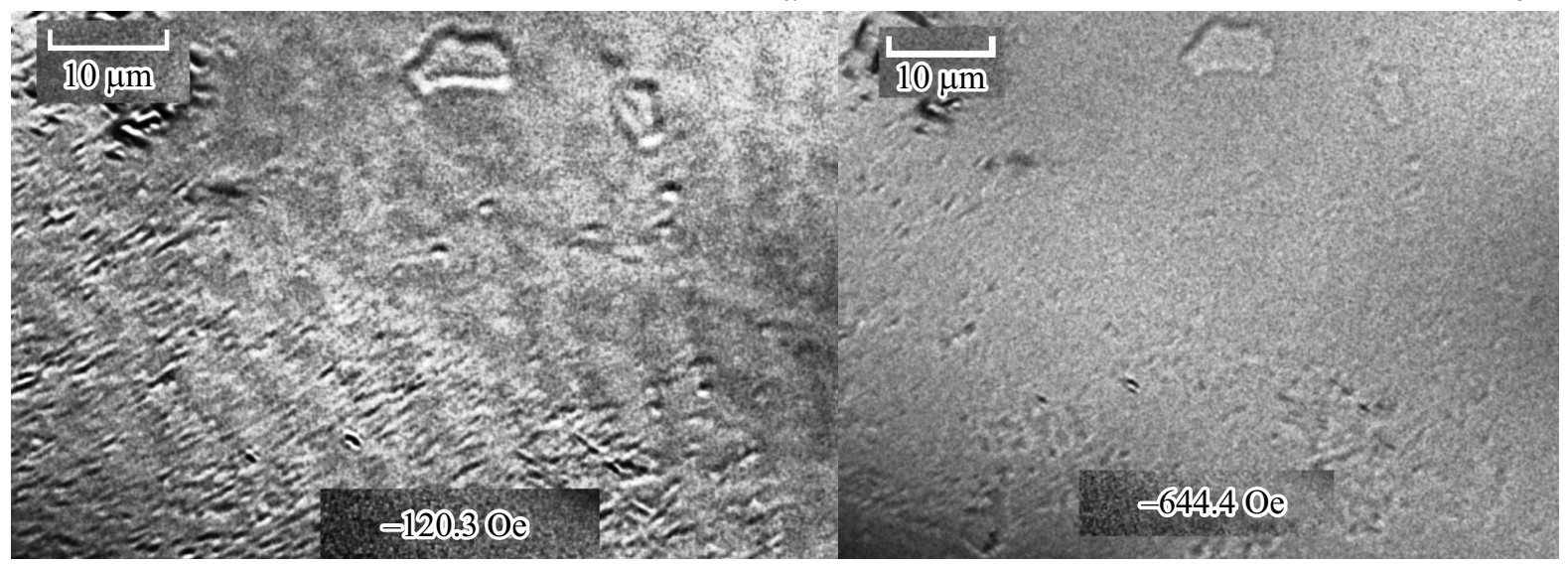

Рис. 3. Изображение одного и того же участка микропровода в микроскопе Керра в продольном магнитных полях -120 Ое $(a)$ и -644 Oе $(b)$.

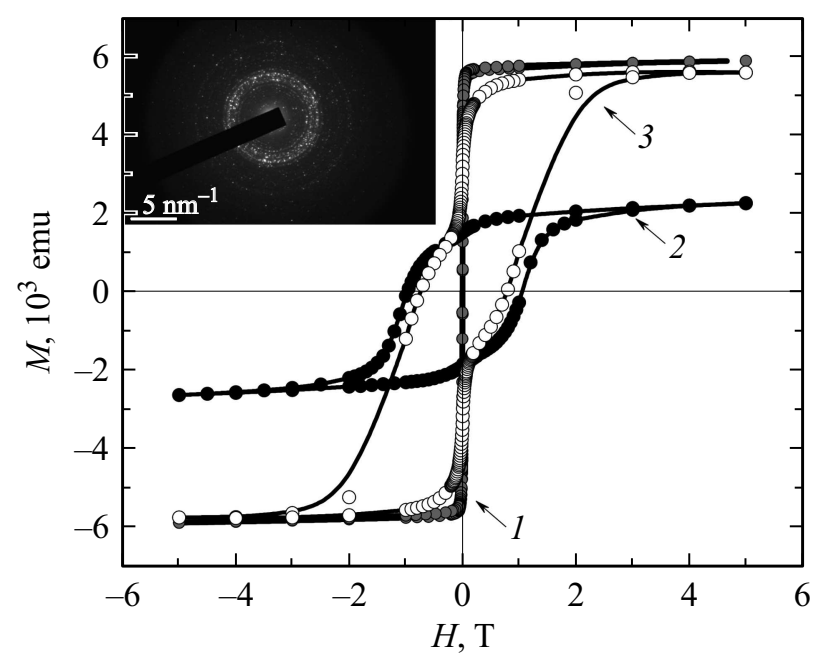

Рис. 4. Петли магнитного гистерезиса микрокристаллических микропроводов PrDy FeCoB: 1 - до отжига, 2 - после отжига $30 \mathrm{~min}$ при $T=900^{\circ} \mathrm{C}, 3-$ после напыления слоя железа. Магнитное поле направлено вдоль образца. На врезке показаны рефлексы электронной дифрактограммы, полученные B HR-TEM.

\section{4. Обсуждение}

Магнитное дипольное и обменное взаимодействия между слоями ядра и оболочки обсуждалось ранее $[10,11]$. В [10] в микропроводах CoFeNiBSiMn/ $\mathrm{Au} / \mathrm{CoNi}$ было обнаружено и точно объяснено влияние магнитного дипольного взаимодействия ядро-оболочка на смещение гистерезиса и переключение намагниченности слоев сердцевины и оболочки. Достаточно толстый промежуточный слой $\mathrm{Au}$ подавляет любую обменную связь между ядром CoFeNiBSiMn и оболочкой $\mathrm{CoNi}$, a наблюдаемый сдвиг поля петли магнитного гистерезиса происходит из-за магнитостатической связи. Соответствующее значение поля смещения $H_{b}$ определяет- ся энергией магнитостатического взаимодействия ядрооболочка, $E_{i n t}$, намагниченностью $M_{i n t}$ и объемом $V$ магнитопровода

$$
H_{b}=E_{\text {int }} / \mu_{0} M_{i n t} V
$$

Для микропровода, длина которого превышает диаметр в $10^{3}$ раз, оценка поля сдвига, вызванного магнитостатической связью, дает очень небольшое поле смещения, обычно $H_{b} \sim 5-10$ Ое [10]. Однако в наших опытах при высокой коэрцитивной силе $H_{c}$ обменное смещение отсутствует даже в микропроводах покрытых железом (рис. 4,a). Это говорит о том, что магнитное дипольное взаимодействие ядра и оболочки микропровода не может объяснить смещения петель гистерезиса, которое, таким образом, имеет обменную природу. Поскольку при взаимной смене материала ядра и оболочки в двухкомпонентной структуре микропровода дипольное магнитного взаимодействие между ядром и оболочкой не изменяется (намагниченность насыщения остается примерно постоянной), возникающие изменения в смещении петли гистерезиса при изменении структуры $\mathrm{PrDyFeCoB}$ можно интерпретировать, как чисто обменный эффект.

Для определения источников обменного смещения подытожим результаты всех экспериментов:

1) в микропроводах с оболочкой, содержащей фазы PrDyFeCoB 1-2, 14-1 и 2-14-1, где включения $\alpha$-Fe возникают самопроизвольно в процессе затвердевания расплава, имеет место обменное смещение 50 Ое при $2 \mathrm{~K}$;

2) в микропроводах с ядром $\mathrm{PrDyFeCoB}$, содержащем фазы PrDyFeCoB 1-2, 14-1 и 2-14-1, и преднамеренно напыленной оболочкой $\alpha$-Fe имеет место обменное смещение $70 \mathrm{Oe}$;

3) в микропроводах с микрокристаллическим ядром PrDyFeCoB, состоящим в основном из фазы 2-14-1, покрытых $\alpha$-Fe обменное смещение отсутствует; 
4) в аморфно-нанокристаллических микропроводах не содержащих оболочки или включений железа, обменное смещение отсутствует.

Из этих данных следует, что присутствие $\alpha$-Fe является обязательным условием возникновения обменного смещения, и одной из границ интерфейса, приводящего к этому эффекту, является $\alpha$-Fe. Фаза 2-14-1 не участвует в формировании обменного смещения. Обсуждая возможность участия фаз 1-2 и 1-4-1 отметим, что в них тяжелые редкоземельные ионы Dу связаны с подрешеткой переходных металлов антиферромагнитным образом и ферримагнитные фазы $\mathrm{Dy}(\mathrm{FeCo})_{2}$ и $\mathrm{Dy}(\mathrm{FeCo})_{4} \mathrm{~B}$ могут на интерфейсе с $\alpha$-Fe давать обменное смещение. Фазы $\operatorname{Pr}(\mathrm{FeCo})_{2}$ и $\operatorname{Pr}(\mathrm{FeCo})_{4} \mathrm{~B}$ с легким элементом $\operatorname{Pr}$ являются ферромагнитными, и поэтому в принципе не могут участвовать в формировании обменного смещения на границе с $\alpha$-Fe.

\section{5. Выводы}

1) В микрокристаллических микропроводах PrDyCoFeB c широкой петлей гистерезиса напыление железа приводит к появлению составной петли гистерезиса с аддитивными вкладами оболочки железа и ядра микропровода, однако при этом не возникает обменного смещения петли гистерезиса. Поскольку основной объем микропровода состоит из микрокристаллов фазы 2-14-1, можно предполагать, что интерфейс этой фазы с $\alpha$-Fe не является источником обменного смещения.

2) В аморфно-нанокристаллических микропроводах PrDyCoFeB c напыленным слоем железа на их поверхность при $2 \mathrm{~K}$ наблюдается обменное смещение $70 \mathrm{Oe}$, которое отсутствует в тех же микропроводах до напыления. Величина обнаруженного эффекта смещения в микропродах с напыленным слоем железа близка к обменному смещению $50 \mathrm{Oе}$ в микропроводах, где включения железа самопроизвольно формировались в ядре микропровода в процессе охлаждения расплава. Знак и величина обменного смещения определяются величиной магнитного поля, приложенного при их охлаждении до $2 \mathrm{~K}$. Это показывает, что причиной смещения является обменное взаимодействие на границе между ферромагнитной фазой $\alpha$-Fе и ферримагнитными фазами $\mathrm{Dy}(\mathrm{CoFe})_{2}$ или $\mathrm{Dy}(\mathrm{CoFe})_{4} \mathrm{~B}$, независимо от способа создания интерфейса ферромагнетик-ферримагнетик.

\section{Финансирование работы}

Работа выполнена в рамках программы ИПХФ РАН АААА-А19-119092390079-8, при поддержке гранта Президента РФ для поддержки ведущих научных школ 2644.2020.2 и гранта РФФИ 20-32-70025 „Стабильность“

\section{Конфликт интересов}

Авторы заявляют, что у них нет конфликта интересов.

\section{Список литературы}

[1] J. Torrejón, M. Vázquez, L.V. Panina. J. Appl. Phys. 105, 033911 (2009).

[2] R.B. Morgunov, O.V. Koplak. Mater. Lett. 273, 127954 (2020).

[3] R.B. Morgunov, O.V. Koplak, V.P. Piskorskii, D.V. Korolev, R.A. Valeev, A.D. Talantsev. J. Magn. Magn. Mater. 497, 166004 (2020).

[4] S. Wang, Y. Liang, F. Ye, G. Geng, J. Lin. J. Mater. Proc. Tech. 249, 325 (2017)

[5] H.L. Seet, X.P. Li, K.S. Lee, L.Q. Liu. J. Mater. Proc. Tech. 192-193, 350 (2007).

[6] K. Pirota, M. Hernandez-Velez, D. Navas, A. Zhukov, M. Vazquez. Adv. Funct. Mater. 14, 266 (2004).

[7] J. Escrig, S. Allende, D. Altbir, M. Bahiana, J. Torrejon, G. Badini, M. Vazquez. J. Appl. Phys. 105, 023907 (2009).

[8] R. Szary, I. Luciu, D. Duday, E.A. Perigo, T. Wirtz, P. Choquet, A. Michels. J. Appl. Phys. 117, 17D134 (2015).

[9] O.V. Koplak, V.L. Sidorov, E.I. Kunitsyna, R. A. Valeev, D.V. Korolev, V.P. Piskorskii, R.B. Morgunov. Phys. Solid State 61, 2061 (2019).

[10] O.V. Koplak, R.B. Morgunov. Mater. Sci. Eng. B 263, 114845 (2021).

[11] J. Escrig, S. Allende, D. Altbir, M. Bahiana, J. Torrejon, G. Badini, M. Vazquez. J. Appl. Phys. 105, 023907 (2009).

[12] Е.Н. Каблов, О.Г. Оспенникова, И.И. Резчикова, Р.А. Валеев, И.В. Чередниченко, Р.Б. Моргунов. Авиационные материалы и технологии S2, 42 (2015).

[13] Е.Н. Каблов, А.Ф. Петраков, В.П. Пискорский, Р.А. Валеев, Е.Б. Чабина. Металловедение и термическая обработка металлов 6, 12 (2005).

Редактор Т.Н. Василевская 